\title{
Evaluation of APACHE II, SAPS II and SOFA as predictors of mortality in patients over 80 years admitted to ICU
}

\author{
JE Romo Gonzales, J Silva Obregón', C Martin Dal Gesso1, P Gallardo Culebradas², S Saboya Sanchez², \\ M Torralba ${ }^{4}$
}

From ESICM LIVES 2015

Berlin, Germany. 3-7 October 2015

\section{Objectives}

Evaluate and compare the predictive ability of APACHE II, SAPS II and SOFA in mortality of elderly patients admitted for medical causes in the ICU of the Hospital Universitario de Guadalajara.

\section{Methods}

Retrospective cohort study. In this study we included patients with at least 80 years admitted to ICU for medical cause, from January-2003 to May 2011. Patients with Ischemic heart disease and arrhythmias were excluded. Logistic regressions analysis was used to calculate the sensitivity, specificity and accuracy as well as the OR probability of mortality. The ability to predict mortality was performed with ROC curves.

\section{Results}

There were analyzed 95 patients, 55/95 (58\%) males. Median age: 81 years (IQR: 80-83 years). Hospital mortality 52/95 (54.7\%). Median APACHE II, SAPS II and SOFA: 23 (IQR 18-29), 7 (IQR: 4-10), 49 (IQR: 40-65).

The sensitivity, specificity and accuracy were respectively $75 \%, 63 \%$ and $69 \%$ for APACHE II; $73.1 \%, 62.8 \%$ and $68.4 \%$ for SOFA; $73.1 \%, 76.7 \%$ and $74.7 \%$ for SAPS II. For every one-point increase in score of APACHE II, SOFA and SAPS II, the possibility of dead increased by $16 \%, 32 \%$ and $13 \%$ respectively $(\mathrm{p}<0.0001$ in all three regressions); coefficient of determination Nagelkerke 0.26, 0.24 and 0.51 respectively. The area under the curve (AUC) of these models was: 0.76 for APACHE II, 0.75 for SOFA and 0.86

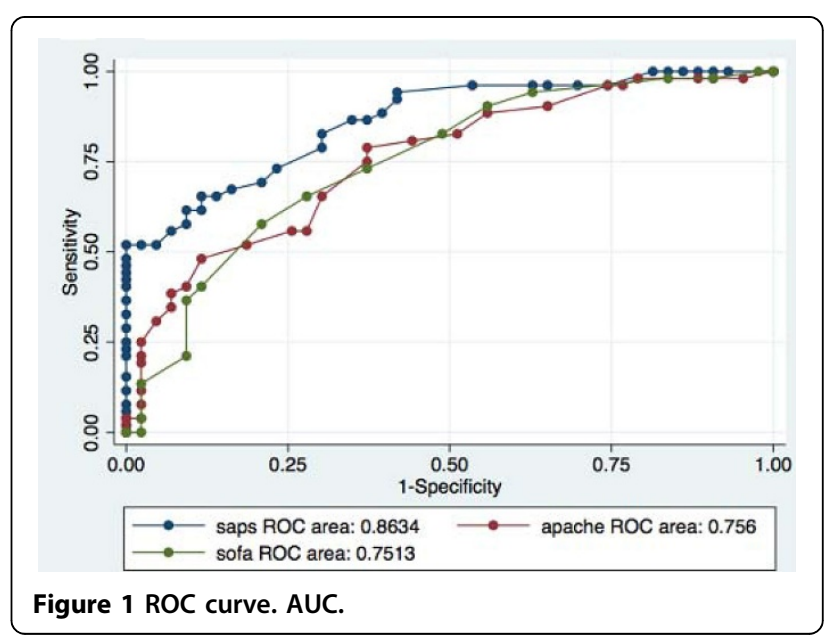

for SAPS; the differences between them were statistically significant $(\mathrm{p}=0.018)$.

\section{Conclusions}

In our series, the SAPS II is the model that best predicts mortality in patients with at least 80 years admitted to ICU for medical reasons.

\section{Authors' details}

${ }^{1}$ Hospital Universitario de Guadalajara, Intensive Care Unit, Guadalajara, Spain. ${ }^{2}$ Hospital Universitario de Guadalajara, Anaesthesiology, Guadalajara, Spain. ${ }^{3}$ Hospital Universitario Puerta de Hierro Majadahonda, Intensive Care Unit, Madrid, Spain. ${ }^{4}$ Hospital Universitario de Guadalajara, Internal Medicine, Guadalajara, Spain.

${ }^{1}$ Hospital Universitario de Guadalajara, Intensive Care Unit, Guadalajara, Spain Full list of author information is available at the end of the article 
Cite this article as: Romo Gonzales et al:: Evaluation of APACHE II, SAPS II and SOFA as predictors of mortality in patients over

80 years admitted to ICU. Intensive Care Medicine Experimental 2015 3(Suppl 1):A343.

\section{Submit your manuscript to a SpringerOpen ${ }^{\mathcal{O}}$ journal and benefit from:}

- Convenient online submission

- Rigorous peer review

- Immediate publication on acceptance

- Open access: articles freely available online

- High visibility within the field

- Retaining the copyright to your article

Submit your next manuscript at $\gg$ springeropen.com 